\title{
Les chemins du savoir en Quercy et Rouergue à l'époque moderne. Alphabétisation et apprentissages culturels
}

\section{Georges Fournier}

\section{(2) OpenEdition \\ 1 Journals \\ Édition électronique \\ URL : https://journals.openedition.org/ahrf/1009 \\ DOI : 10.4000/ahrf.1009 \\ ISSN : 1952-403X \\ Éditeur : \\ Armand Colin, Société des études robespierristes}

\section{Édition imprimée}

Date de publication : 1 décembre 2000

Pagination : 163

ISSN : 0003-4436

\section{Référence électronique}

Georges Fournier, «Les chemins du savoir en Quercy et Rouergue à l'époque moderne.

Alphabétisation et apprentissages culturels ", Annales historiques de la Révolution française [En ligne], 322 | octobre-décembre 2000, mis en ligne le 27 avril 2006, consulté le 23 avril 2022. URL : http:// journals.openedition.org/ahrf/1009; DOl : https://doi.org/10.4000/ahrf.1009

Ce document a été généré automatiquement le 23 avril 2022.

Tous droits réservés 


\title{
Les chemins du savoir en Quercy et Rouergue à l'époque moderne. Alphabétisation et apprentissages culturels
}

\author{
Georges Fournier
}

\section{RÉFÉRENCE}

Guy Astoul, Les chemins du savoir en Quercy et Rouergue à l'époque moderne. Alphabétisation et apprentissages culturels, Toulouse, Presses universitaires du Mirail, 1999, $392 \mathrm{p}$.

1 Il n'est pas besoin d'insister sur la place tenue par l'alphabétisation parmi les facteurs de l'acculturation politique, et l'on sait combien les révolutionnaires ont cherché dans l'ignorance, celle des ruraux en particulier, une explication, parfois trop facile d'ailleurs, aux résistances populaires à la Révolution. L'historiographie a depuis longtemps classé le Sud-Ouest au rang des régions les plus marquées, jusqu'au milieu du xixe siècle, par un analphabétisme massif. L'édition abrégée de la thèse de Guy Astoul permet de réviser ce jugement. La démonstration repose pour l'essentiel sur la remise en cause du critère des signatures au mariage sur des registres paroissiaux très mal tenus, alors que les registres notariaux offrent dans le Midi une source beaucoup plus sûre.

2 Si les progrès de l'alphabétisation au xvire siècle, surtout encouragés par la rivalité protestants / catholiques, sont restés limités, il n'en va pas de même au xvIIIe, surtout après 1750. Le souci de l'instruction dépasse alors les motivations religieuses pour s'insérer dans des stratégies de promotion sociale, plus ou moins élaborées selon les milieux. Malgré les résistances suscitées chez certains notables par ce nouveau contexte les écoles se multiplient, plus que ne l'indiquent des documents officiels peu révélateurs de formes très diverses, parfois rudimentaires ou précaires. D'où d'ailleurs, 
dans certains cas, des acquis limités à la capacité de déchiffrer laborieusement l'imprimé en français, celui justement du libelle ou de l'affiche, ce qui en matière d'acculturation politique n'est pas négligeable. Pour l'écrit reste le test des signatures, critère certes difficile à interpréter, mais Guy Astoul estime que dans la région étudiée elles sont dans $90 \%$ des cas d'une qualité graphique convaincante. Entre 1776 et 1785 sur $20 \%$ de la population rurale du diocèse de Montauban pour lesquels la comparaison est possible, 1marié sur 15 a signé le registre paroissial, presque 1 sur 4 les registres notariés. Dans les campagnes du Bas-Quercy, 1 marié sur 10 est capable de signer à l'église, 1 sur 5 chez le notaire. Dans les villes, où l'écart paraît négligeable entre registres paroissiaux et notariaux, l'alphabétisation masculine serait de l'ordre de $39 \%$, avec de grandes variations selon les quartiers. De façon générale elle reflète naturellement les hiérarchies sociales : $8 \%$ chez les journaliers, $13 \%$ chez les brassiers, autour de $50 \%$ dans la paysannerie relativement aisée ou l'artisanat du fer et du cuir. Les zones d'habitat dispersé donnent les taux les plus faibles. Quant aux femmes, leur analphabétisme paraît d'autant plus massif qu'elles sont souvent, de façon significative, représentées par le père ou le frère aîné dans les actes notariés.

Au total, pour les 110000 habitants de l'élection de Montauban, Guy Astoul conclut à une alphabétisation masculine de $28 \%$, soit $10 \%$ de mieux que les chiffres de l'enquête Maggiolo. Cet élargissement se traduit par la constitution d'une catégorie de petits notables entre le peuple et les élites, intermédiaires culturels qui, tout en pratiquant le bilinguisme, renforcent les positions de la langue française et assurent un encadrement social propice aux initiatives locales, en particulier en milieu rural. Par ce canal se diffusent les idées nouvelles et un esprit contestataire qui tend à substituer l'action juridique à la violence (cf. l'article de Guy Astoul, « Solidarités paysannes... », A.H.R.F., $\mathrm{n}^{\circ}$ 311).

4 Sans remettre en cause, par rapport à certaines régions, l'idée d'un retard, dont il analyse les raisons, Guy Astoul relativise l'analphabétisme des populations du Sud-Ouest. Il le replace dans "un système de représentations, de pouvoirs et de rapports sociaux ». Il met ainsi en évidence la réalité d'une aspiration populaire à l'instruction qui transforme les mentalités collectives et place déjà l'école "au cœur des processus de transformation de la société ». 